\section{Geothermal energy}

Problems persist

Two 2,000-metre boreholes for tapping geothermal heat in "hot dry rock" in Cornwall, England, by pumping water down one and out of the other, were "hydrofractured" just before Christmas to connect the two wells - but they remain stubbornly disconnected.

Cracks opened by the hydrofracturing (pressurizing the wells with water) have spread almost exactly along the plane of the wells, at right angles to the preferred direction (see figure). And on-line seismic mapping has indicated that the cracks have developed mostly downwards, rather than across the rock between the wells and have confined themselves to a narrow plane.

The result, according to Dr Tony Batchelor, director of the project, is that there is no direct, low-resistance flow path between the wells. Water flow between the two holes is thus only a fraction of that hoped for, and the thermal power extracted correspondingly reduced to $1 \mathrm{MW}$ although it had been calculated that $30 \mathrm{MW}$ might be available from the Cornish wells.

Even so, the Geothermal Energy Project of the Camborne School of Mines, which is responsible for the experiment, claimed that the $£ 10$-million exercise had been " 80 per cent successful"; and Professor E.R. Oxburgh at the University of Cambridge described the results as "phenomenal".

The reason: Camborne techniques, which use an explosive charge to initiate cracks in the rock, followed by water pumping to open the natural joints, appear to have created a crack system more than 2 million $\mathrm{m}^{2}$ in area and $100-200 \mathrm{~m}^{3}$ in volume. This is the scale of a major reservoir, and confirms the Camborne approach, says Oxburgh. The fact that the

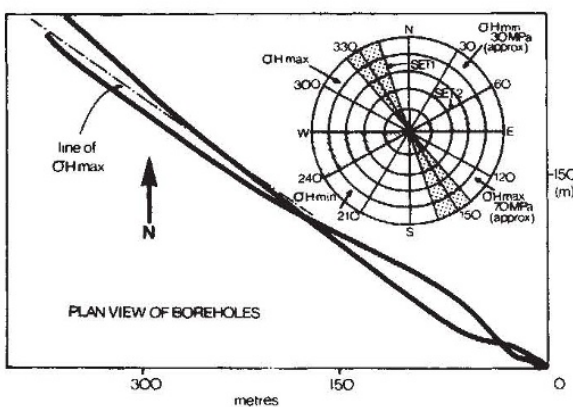

The compass rose indicates the directions of maximum and minimum horizontal stres (o Hmax and Hmin) in the rock, and the planes of the principal pre-existing joints in the formation (which are rotated slightly with respect to the present stress). Despite appearances, the holes nowhere intersect. The upper parts of the holes are cased, allowing water pumped down one to pass to the other through cracks in the hot granite. An explosive charge followed by water pumping at high pressure opened up a large surface area of joints zig-zag fashion almost parallel to the drill holes. The rock thus opened against the direction of minimum stress, rather than along natural joint planes. cracks are parallel to the holes and mostly beneath them can be corrected with a third borehole, drilled to cross the cracks - at a cost approaching another $£ 2$ million.

The Camborne team expects to get its money as the first holes were considered experimental; and the UK Department of Energy, which paid $£ 8.8$ million towards the present holes (the balance having come from the European Commission), has "given permission" for a third hole.

But why do the existing holes seem to have been so "wrongly" placed, along the plane of maximum horizontal stress? It is partly bad luck: the holes. were drilled to lie roughly between the planes of existing natural cracks, in the hope that either one or other would open when the holes were hydrofractured. In the event, the cracking opened along a zig-zag line in a plane determined by rock stresses, and the maximum stress happened to lie in the plane of the holes.

What is also clear, with hindsight, is that the stress directions were predictable. They were determined by tectonic forces in Europe and they correspond to stresses measured in a mine just ten miles from the drill site. However, what was unpredictable was the ratio between maximum and minimum stress. This has turned out to be high, and so determined the crack plane more effectively than the existing natural jointing structure.

Robert Walgate

\title{
Solidarity members to lose jobs
}

A MAJOR "reorganization" last month at the Nuclear Research Institute at Swierk, near Warsaw, has meant the "redundancy" of more than 60 former Solidarity activists, according to reports from the Solidarity underground in Warsaw.

Almost all those involved held senior scientific posts in the institute, many of the rank of full or associate professor. The proton synchrotron team, in particular, has been hard hit.

The chance of the redundant scientists finding appropriate employment in Poland seems remote. There is no unemployment benefit in Poland, and although the local underground committees of Solidarity still try to organize financial relief, their resources are stretched. Emigration would appear the best hope, but it is by no means certain that the authorities would grant visas to those affected.

The Swierk redundancies have raised fears that similar reorganizations may take place at other academic institutions where, formerly, Solidarity was particularly strong. Already there are signs of a coming shake-up in the Warsaw University Psychology Department, which was closed for three weeks in November following a protest strike.

Vera Rich

\section{Medical research}

\section{Mandatory ethics recomendations}

\section{Canberra}

THE National Health and Medical Research Council (NH and MRC) which administers a quarter of the total funds spent on medical research and development in Australia, has established a National Medical Research Ethics Committee which met for the first time on 13 December last year. The council will also write to all state and territory ministers of health recommending that it be made mandatory for all universities and hospitals in which medical research is undertaken to have institutional ethics committees and that the NH and MRC's recently revised statement and supplementary be brought to their attention.

Its predecessor, the now disbanded Working Party on Medical Research, which recommended the setting up of the national body as well as revising the $\mathrm{NH}$ and MRC statement on human experimentation, was asked to look among other things at: (1) research on children, the mentally ill and those independent relationships; (2) therapeutic trials (3) in vitro fertilization and embryo transfer. Their conclusions were attached as supplementary notes to the NH and MRC statement.

At present all proiects funded by $\mathrm{NH}$ and MRC must comply fully with the NH and MRC statement and be cleared by institutional ethics committees. Although many other bodies administering grants for medical research also require prior approval by an institutional ethics committee, guidelines for approval may be arbitary. Consequently the recommendation to states and territories will go some way towards creating the conditions for uniform requirements for all medical research projects and universal acceptance of $\mathrm{NH}$ and MRC guidelines in a country where health is a state government responsibility.

Under the chairmanship of Richard Lovell, professor of medicine at the University of Melbourne, the National Medical Research Ethics Committee will review ethical considerations of medical research and respond to questions referred to it by institutional ethics committees and government agencies. Its role in augmenting the authority of institutional ethics committees is a delicate one. Nevertheless, according to the working party report last August, it could, "by virtue of its well-informed and respected membership, act with such authority that uncooperative institutions and workers would see themselves as vulnerable'".

Vimala Sarma 